\title{
O mecanismo de desenvolvimento limpo como mitigador do aquecimento global e a participação do Brasil
}

Raimundo Garcia Cota - PhD. Professor da Faculdade de Economia e do Programa de Pós-Graduação em Economia (PPGE) da UFPA.

Maria Aparecida Martins Cardoso Reis - Bacharela em Ciências Econômicas pela Universidade Federal do Pará (UFPA).

Lorena Alves do Vale - Bacharela em Direito e pós-graduanda em Economia e Desenvolvimento Regional pela Faculdade de Economia da UFPA.

\section{Resumen}

Este estudo, de relevância econômicoambiental, parte do problema do aquecimento global para analisar o Mecanismo de Desenvolvimento Limpo (MDL) como uma ferramenta capaz de contribuir para a mitigação dos gases de efeito estufa (GEE) por meio do cumprimento de metas de redução de emissões pré-estabelecidas pelo Protocolo de Quioto. Examina-se e participação do Brasil como país hospedeiro dos projetos do MDL. Conclui-se que, embora a implementação do MDL diminua o custo global de redução de emissões de gases estufa pelos países desenvolvidos e apóie iniciativas que promovam o desenvolvimento sustentável, a falta de maior especificidade nas regras do mecanismo pode abrir precedentes ao direito de poluir. Entende-se que o mecanismo não deve restringir-se somente ao cumprimento de meta, mas é fundamental que atue como desestimulante da poluição em sua origem, conforme a proposta de sustentabilidade, norte da política ambiental climática.

\section{Palavras-chave}

Protocolo de Quioto. Mercado de carbono. Mecanismo de desenvolvimento limpo.

\begin{abstract}
This study of economic-environmental relevance emerges from the problem of the Global Environment in order to analyze the Mechanism of Clean Development (MCD) as an efficient tool, which can contribute to the mitigation of the Greenhouse Effect Gases (GEG) through the fulfilling of emission reduction goals pre-established by Kyoto Protocol. One examines the participation of Brazil as a hosting country of MCD projects. One concludes that, although the implementation of the MCD reduces the global cost of reduction of greenhouse gases emissions by developed countries and supports initiatives which promote sustainable development, the lacking of major specificity in the rules of the mechanism can open precedents to the right of polluting. One understands that the mechanism cannot be restricted only to the fulfillment of goals, but it is fundamental that it works as discouragement of pollution in its origin, according to the proposal of sustainability, north of the weather environmental policy.
\end{abstract}

\section{Keywords}

Kyoto Protocol. Carbon Market. Mechanism of Clean Development. 


\section{INTRODUÇÃO}

\section{O AQUECIMENTO GLOBAL: ORIGEM E POSSÍVEIS SOLUÇÕES}

Este artigo tem por objetivo verificar se o Mecanismo de Desenvolvimento Limpo (MDL) (BRASIL, 2002), criado pelo Protocolo de Quioto (BRASIL, 1997) para mitigar o efeito estufa, é uma ferramenta econômica que legitima o direito de poluir e se esse mecanismo está conseguindo promover a sustentabilidade ambiental.

Após a Revolução Industrial, o ser humano iniciou a destruição dos ecossistemas pensando no seu bem-estar; buscou o desenvolvimento econômico a qualquer custo, sem nenhuma preocupação com os impactos que poderia causar ao meio ambiente, acreditando que a natureza estava à sua disposição e, principalmente, por tempo interminável.

Foi apenas inteligente o suficiente para criar novas formas de sobrevivência e desenvolver novas tecnologias. Só não foi suficientemente perceptivo no sentido de observar que suas ações destruíam o seu próprio habitat e que a conta dessa destruição seria cobrada pela natureza, das gerações futuras.

Ocorre que a sociedade contemporânea desenvolveu-se pautando-se por um paradigma científico segundo o qual a natureza é vista como objeto que o ser humano busca conhecer para dominar e usar. Nesse fosso, o conhecimento torna-se utilitarista e subserviente a grupos de interesses dominantes a fim de atender a demanda da produção capitalista. Isso inevitavelmente resultou, dentro da ciência, na separação entre sujeito e objeto, ou seja, entre a sociedade e a natureza (CAPRA, 2003, p. 25 e p. 56).

Adotou-se, desde então, um modelo de vida calcado no antropocentrismo e no racionalismo exacerbado, nos quais a ciência tornou-se dogma e qualquer outro conhecimento passou a ser mito. Para a ciência econômica convencional, a natureza é considerada apenas como um espaço onde se captam recursos, se realizam experiências e se excretam dejetos.

Contudo, não demorou muito para que a natureza desse respostas ao modo como o homem a tratava, passando os efeitos colaterais da economia a serem nocivos, não somente à sociedade, mas também a ela mesma. Quando a natureza não consegue absorver as quantidades de dejetos e efluentes resultantes da produção e do consumo de bens e serviços, eles são convertidos em externalidades negativas ${ }^{1}$ para a sociedade. Isto é, a sociedade passa a perder bem-estar por conta da poluição do sistema econômico e não é compensada.

\footnotetext{
1 As externalidades negativas manifestam-se quando o preço de uma mercadoria não incorpora os custos socioambientais resultantes da sua produção e de seu consumo.
} 
No início do século XX, alguns economistas neoclássicos como Pigou (1920) e Coase (1960) mostraram certa preocupação com a exploração predatória dos recursos naturais e com a poluição, ainda que a motivação primeira fosse a maximização das utilidades dos produtos e serviços pelos indivíduos (apud ROMEIRO, 2003, p. 10). As possíveis soluções encontradas orbitavam em torno da ideia de realocação dos recursos naturais, com a aplicação de taxas pelo Estado para neutralizar o dano ou o estabelecimento do direito de propriedade. Contudo, o problema ambiental ainda não era o maior objetivo.

Somente a partir dos anos 80, os problemas ambientais ficaram mais evidentes e chamaram a atenção da comunidade internacional e dos governos. Um dos problemas mais graves decorrentes do histórico processo produtivo poluente é o aquecimento global. Atualmente existem evidências inequívocas da participação humana nesse processo (BRASIL, 2007) $)^{2}$, e um dos fatores que corroboram para tanto é o aumento de gases de efeito estufa (GEE) ${ }^{3} 6$ na atmosfera, de origem antropogênica.

A principal evidência do aquecimento global vem das medidas de temperatura de estações meteorológicas em todo o mundo desde 1860. As previsões apontam para um crescimento significativo da maioria de GEE nos próximos 100 anos. A temperatura global, à superfície, que aumentou $0,7^{\circ} \mathrm{C}$ nos últimos 100 anos, deverá crescer entre 1.4 a $5.8^{\circ} \mathrm{C}$, até 2100 . Os padrões espaciais e temporais da precipitação, já em mudança, deverão sofrer novas alterações. $\mathrm{O}$ nível do mar aumentou 10 a 25 centímetros no último século e deverá subir de 18 a 88 centímetros (PORTUGAL, 2006, p. 3).

Quase três quartos das emissões de gás carbônico $\left(\mathrm{CO}_{2}\right)$ para a atmosfera, nos últimos 20 anos, resultam da queima de combustíveis fósseis, enquanto o restante deve-se predominantemente às mudanças no uso da terra, especialmente ao desmatamento.

Atualmente a concentração de gás carbônico na atmosfera é de aproximadamente 450 partes por milhão (ppm) em volume; futuramente, os níveis de $\mathrm{CO}_{2}$ deverão ser ainda maiores. Segundo o Relatório Especial de Cenários de Emissão (Special Report on Emissions, originariamente) do Painel Intergovernamental sobre Mudanças Climáticas (BRASIL, 2007), a concentração de $\mathrm{CO}_{2}$ em 2100 estará variando entre 541 e 970 ppm, o suficiente para causar catástrofes irreversíveis.

No Brasil, as fontes básicas de maior contribuição de emissões antrópicas

\footnotetext{
${ }^{2}$ O Quarto Relatório do Painel Intergovernamental de Mudanças Climáticas (IPCC, em inglês) revela que são inequívocas as causas antropogênicas do processo de aquecimento global.

3 Dióxido de carbono $\left(\mathrm{CO}_{2}\right)$, metano $\left(\mathrm{CH}_{4}\right)$, óxido nitroso $\left(\mathrm{N}_{2} \mathrm{O}\right)$, hidrofluorcarbonos $(\mathrm{HFC})$, perfluorcarbonos (PFC) e hexafluoreto de enxofre $\left(\mathrm{SF}_{6}\right)$.
} 
de $\mathrm{CO}_{2}$ são principalmente o aumento do desmatamento, bem como o tráfego de veículos e a combustão industrial. De modo simplificado, pode-se dizer que as emissões de $\mathrm{CO}_{2}$ derivam do processo de liberação do carbono contido na biomassa quando ocorre a derrubada da floresta e, posteriormente, a queimada.

Segundo previsões divulgadas pelo IPCC (BRASIL, 2008) em seu Quarto Relatório, até a metade do século, os aumentos de temperatura e, consequentemente, a diminuição de água nos solos causarão uma substituição gradual das florestas tropicais por savanas na Amazônia Oriental. A vegetação semiárida será substituída por vegetação de terras áridas, podendo ocorrer perdas importantes da biodiversidade devido à extinção de espécies em numerosas áreas da América Latina.

Diante das incertezas quanto à exatidão das alterações climática previstas para o futuro, visto que essas alterações variarão de região para região ao redor do globo, há um amplo consenso por parte de cientistas, nações, empresas e cidadãos quanto à necessidade de buscar soluções efetivas para evitar a catástrofe que abalará a vida no planeta.

Desse modo, as políticas ambientais representam um grande avanço em relação a esse intento internacional. Ao longo deste artigo, analisaremos um intrumento econômico que nasceu com o Protocolo de Quioto: o Mecanismo de Desenvolvimento Limpo (MDL). Devido à sua amplitude e à sua importância no contexto do capitalismo, o MDL tem sido utilizado pelos países desenvolvidos para ajudá-los a cumprir suas metas de redução de emissões assumidas.

$\mathrm{O}$ estudo tem ainda o objetivo de examinar a potencialidade do MDL para alcançar a mitigação do efeito estufa. Verificar-se-á o risco de seu uso como instrumento que legitima a poluição, assim como a participação do Brasil e sua viabilidade econômica no mercado de carbono.

Neste artigo, será demonstrada a relação entre a interferência antrópica no ecossistema global e as alterações climáticas que redundam no aquecimento global. Para isso, serão apresentados fatos e dados estatísticos resultantes de pesquisas científicas que comprovam também a contribuição da atividade humana, direta ou indireta, para a crise ecológica atual do planeta. Sabemos que a mudança no clima afeta diretamente a produção agrícola e, consequentemente, o agronegócio, entre outros setores da economia. Por conseguinte, a produção de alimentos também será afetada juntamente com a economia, o que influenciará diretamente o preço dos alimentos para o consumidor final, principalmente o de baixa renda.

$\mathrm{O}$ artigo será finalizado com uma abordagem do mercado financeiro que se gerou dentro do MDL - o lucrativo mercado do carbono -, no qual os gases responsáveis pelo efeito estufa, convertidos em créditos de carbono, tornaram-se 
uma espécie de moeda no século XXI. Pretende-se ainda expor o potencial dessa ferramenta de mercado para o desenvolvimento sustentável, demonstrando-se a interdependência existente entre o meio ambiente e o sistema econômico.

\section{MECANISMOS UTILIZADOS NA MITIGAÇÃO DO AQUECIMENTO} GLOBAL

\subsection{Protocolo de Quioto}

Quando a comunidade científica anunciou a gravidade dos efeitos da ação antrópica sobre o clima, relacionando-a às anormalidades climáticas do planeta (IPCC, 1990), a Assembleia Geral das Nações Unidas resolveu estabelecer, no mesmo ano, o Comitê Intergovernamental de Negociação para a ConvençãoQuadro sobre Mudança do Clima.

Em 9 de maio de 1992, com a presença de representantes de aproximadamente 150 nações, foi elaborada a Convenção-Quadro das Nações Unidas sobre Mudanças Climáticas (CQNUMC) na Sede das Nações Unidas (Nova York). Seu objetivo é a estabilização das concentrações de GEE na atmosfera em um nível em que a ação antrópica não seja perigosa ao clima.

Em junho de 1992, no Rio de Janeiro, 155 países firmaram a Convenção na Conferência das Nações Unidas sobre o Meio Ambiente e Desenvolvimento, conhecida como "Cúpula da Terra" (RIO/92), com base nos princípios de precaução e de responsabilidades comuns diferenciadas.

A CQNUMC foi criada com o objetivo bem sedimentado de traçar um diagnóstico do quantum dos principais gases causadores do efeito estufa (GEE) na atmosfera e, principalmente, de reunir esforços para conseguir sua estabilização. Pelo fato de ser o primeiro passo em direção à estabilização do clima, não houve nenhum tipo de acordo obrigatório, porém foi sugerido aos países industrializados que mantivessem, até 2000, os mesmos índices de emissão do ano de 1990. Durante as discussões, os países chegaram à conclusão de que todos, independentemente de seu tamanho, devem assumir a responsabilidade de conservar e preservar as condições climáticas.

Segundo o princípio da precaução, as nações não devem postergar a adoção de medidas que possam prever, minimizar ou mesmo evitar as causas das mudanças climáticas e seus possíveis efeitos adversos, baseando-se no fato da não comprovação científica.

O princípio das responsabilidades comuns diferenciadas fundamenta-se na tese de que a maior parte das emissões históricas e atuais de gases provém dos países mais desenvolvidos. As emissões advindas dos países subdesenvolvidos 
ainda são consideradas baixas, porém, devem aumentar à medida que precisem suprir suas demandas socioeconômicas.

Com base nesses dois princípios, foram estabelecidos dois grupos de países: as "Partes Anexo I", que compreendem os países desenvolvidos signatários da Convenção e os países industrializados da antiga União Soviética e do Leste europeu, e as "Partes não Anexo I", que compreendem as Partes não listadas no Anexo I, entre as quais o Brasil.

A partir de então, todos os anos, os membros signatários da ConvençãoQuadro (CQNUMC) passaram a reunir-se em conferências a fim de concretizar o maior objetivo da Convenção: a mitigação do efeito estufa.

Na primeira sessão da Conferência das Partes (COP-1), realizada um ano após a Convenção, em 1995, na Alemanha, foi criado o Mandato de Berlim. Essa resolução estabeleceu que os países desenvolvidos, baseados no princípio da responsabilidade comum diferenciada, deveriam definir um Protocolo ou outro instrumento legal, do qual constassem algumas limitações quantificadas de redução de suas emissões antrópicas, por meio de fontes e remoções de sumidouros de gases poluentes não controlados pelo Protocolo de Montreal. Além disso, deveriam descrever as políticas e as medidas que seriam necessárias para atingir essas metas. Esse documento foi assinado por cerca de 2400 cientistas de diversas áreas e 2600 economistas, entre os quais alguns ganhadores do Prêmio Nobel, preocupados com as mudanças climáticas (BRASIL, 2008).

O Protocolo de Montreal, do qual participaram 191 países, refere-se às substâncias que destroem a camada de ozônio (SDO). Ele obriga seus signatários a trabalhar para eliminar a produção e o consumo de SDO a partir de cotas prédefinidas, ao mesmo tempo que foram desenvolvidas tecnologias alternativas para reduzir ou eliminar os riscos para a camada de ozônio (BRASIL, 2008).

Em 1996, foi realizada na Suíça a COP-2, durante a qual foi assinada a Declaração de Genebra, contemplando um acordo cujo objetivo era a redução de emissões de $\mathrm{CO}_{2}$. Após longas negociações, as Partes integrantes da CQNUMC decidiram que os compromissos estabelecidos na Convenção para os países do Anexo I não eram suficientemente capazes de combater a mudança climática global.

Em 1997, na cidade de Quioto (Japão), com representantes de mais de 159 nações, foi realizada a COP-3, na qual foi celebrado o Protocolo de Quioto. Seu objetivo era a redução da emissão de GEE e o combate ao aquecimento global. Esse acordo internacional sobre o meio ambiente estabelece, em seu artigo 3. ${ }^{\circ}$, item um, que as Partes do Anexo I deverão reduzir suas emissões de GEE no 
Primeiro Período de Compromisso, compreendido entre 2008 e $2012^{4}$, a uma média de 5,2\% abaixo dos níveis de 1990 (dióxido de carbono, óxido nitroso e metano) e de 1995 (hexafluoreto de enxofre e famílias de hidrofluorcarbonos).

De acordo com o $\int 1 .^{\circ}$ do artigo 25 do Protocolo, o acordo entraria em vigor no prazo de 90 dias após a data em que pelo menos 55 países (que juntos corresponderiam a pelo menos 55\% das emissões globais de GEE em 1990 das Partes incluídas no Anexo I) tivessem depositado seus instrumentos de ratificação, aceitação, aprovação ou adesão. Isso significava um compromisso legal dentro do Protocolo, vinculando todas as Partes envolvidas e submetendo a penalidades os países não complacentes.

No Protocolo, foram incluídos três mecanismos de flexibilização, no intuito de permitir que os países com as maiores emissões e com altos custos de redução possam cumprir suas responsabilidades, investindo em projetos de redução em outros países, cujo custo seria mais baixo. São eles: Comércio de Emissões, Implementação Conjunta e Mecanismo de Desenvolvimento Limpo (MDL).

A COP-4 (1998), realizada na Argentina, teve como objetivo original a negociação de prazos finais para um programa de trabalho voltado para a regulamentação do MDL. Nessa conferência, foram reiterados os compromissos estabelecidos na COP-3, visando implementar e ratificar o Protocolo de Quioto, e foi reforçada a ideia de que é preciso considerar não apenas as emissões atuais, mas também a responsabilidade histórica. Nessa conferência, o Protocolo foi aberto à assinatura para sua ratificação. Os Estados Unidos assinaram, sem, no entanto, ratificá-lo.

Como resultado da reunião, foi criado o Plano de Buenos Aires, que determinou o ano de 2000 como data limite para colocar em prática as regras e questões técnicas e políticas referentes à implantação do Protocolo.

A COP-5 (1999), realizada em Bonn (Alemanha), teve como principais decisões a implementação do Plano de Buenos Aires, o desenvolvimento e a transferência de tecnologias, a capacitação das Partes não Anexo I, mecanismos de flexibilização, o uso da terra e a implementação do artigo 4 . $^{\circ}$ do Protocolo de Quioto.

A COP-6 (2000) ocorreu em Haia, nos Países Baixos, porém não foi concluída ,devido a desacordos entre Estados Unidos e União Europeia. Em 2001, a COP-6 foi retomada na Alemanha e ficou conhecida como COP-6 $1 \frac{1}{2}$. Seu principal resultado foi o Acordo de Bonn, firmado em 23 de julho de 2001, que

4 Trata-se do primeiro período de metas de estabilização de GEE da Convenção-Quadro, que foi definido pelo Protocolo de Quioto e expira em 2012. Esse primeiro período termina, porém começam as etapas seguintes (CENTRO DE GESTÃO E ESTUDOS ESTRATÉGICOS, 2008, p. 47). 
define as medidas de aplicação do Protocolo de Quioto e que deveria ser detalhado e concluído na Conferência das Partes subsequente.

Na sétima Conferência das Partes (COP-7), realizada no Marrocos (2001), celebrou-se o Acordo de Marraquexe, que regulamentou o Mecanismo de Desenvolvimento Limpo (MDL), definindo modalidades e procedimentos de quantificação de emissões.

A COP-8 (2002) ocorreu em Nova Deli (Índia), onde foi dada continuidade ao estabelecimento de modalidades e procedimentos do MDL.

A COP-9 (2003), na cidade de Milão (Itália), deu prosseguimento aos debates sobre a ratificação do Protocolo de Quioto e do desenvolvimento do MDL, com destaque para a questão da regulamentação de sumidouros de carbono. Entretanto, a decisão mais esperada da reunião, que seria a ratificação do Protocolo de Quioto pela Rússia, acabou não ocorrendo.

A COP-10 (2004), em Buenos Aires (Argentina), foi marcada pelo fato de ter sido realizada logo após a ratificação do Protocolo de Quioto por parte da Rússia, o que permitiu sua entrada em vigor em 16 de fevereiro de 2005.

A partir da entrada em vigor do Protocolo, passou a ocorrer, paralelamente à reunião da Conferência das Partes $(\mathrm{COP})$, a reunião das Partes do Protocolo de Quioto (MOP). Assim, a COP-11, no Canadá (2005), foi também a 1. ${ }^{a}$ Reunião das Partes do Protocolo de Quioto (MOP1). Pela primeira vez, a questão das emissões originadas do desmatamento tropical e das mudanças no uso da terra foi oficialmente aceita nas discussões no âmbito da Convenção.

A COP-12/MOP2 aconteceu no Quênia (2006). Representantes de 189 nações assumiram o compromisso de revisar o Protocolo de Quioto, e regras foram estipuladas para o financiamento de projetos de adaptação em países pobres. O governo brasileiro propôs oficialmente a criação de um mecanismo que promovesse efetivamente a redução de emissões de gases de efeito estufa em países em desenvolvimento, oriundas do desmatamento.

A COP-13/MOP3 teve lugar na Indonésia (2007). A decisão mais importante foi a inclusão, pela primeira vez, da questão das florestas no texto da decisão final da Conferência, para ser considerada no próximo tratado climático. Estabeleceu-se um prazo até 2009 para definir as metas de redução de emissões oriundas do desmatamento em países em desenvolvimento pós-2012.

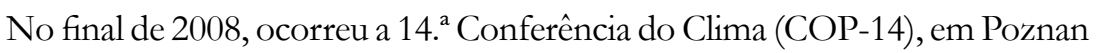
(Polônia). Como tema principal, discutiram-se as propostas para o novo acordo climático que substituirá o Protocolo de Quioto, depois de 2012.

O Brasil pretende apresentar uma solução para colocar em prática a proposta 
de Emissões Reduzidas do Desmatamento e Degradação (REDD). Segundo o ministro do Meio Ambiente, Carlos Minc, o Fundo Amazônia é justamente um exemplo do funcionamento das REDD, que deve ser um ponto-chave no acordo pós-Quioto.

Segundo o Protocolo, os países não pertencentes ao Anexo I, entre os quais o Brasil, continuam sem a obrigação de reduzir suas emissões durante o período de 2008 a 2012. Contudo, esta isenção já está sendo revista, no sentido de se incluírem esses países no próximo período de compromisso (pós-2012).

Ainda é cedo para dizer se o Protocolo de Quioto será bem-sucedido em seus objetivos. Além disso, também não é possível afirmar que o cumprimento das metas estabelecidas no Protocolo terá efeito significativo sobre as mudanças climáticas globais.

De um lado, persiste a recusa dos Estados Unidos a participar de acordos globais de redução de emissões que não estabeleçam metas de redução para países em desenvolvimento; por outro lado, essas incertezas criam, a princípio, dois tipos de perspectivas para o que ocorrerá após o término do prazo de duração do Protocolo de Quioto.

Uma perspectiva será a inexistência, após 2012, de um novo compromisso, que será discutido a partir de dezembro de 2009. Por outro lado, caso haja um segundo período de compromisso, o novo acordo também incluirá os países em desenvolvimento entre aqueles obrigados a reduzir as emissões, a fim de eliminar uma das principais críticas dos Estados Unidos e, com isso, trazê-los para o acordo.

Tendo em vista essas perspectivas, é importante que as oportunidades criadas pelo Protocolo de Quioto para o Brasil, principalmente no que diz respeito ao desenvolvimento de projetos do MDL, sejam plenamente aproveitadas durante o primeiro período de compromisso. Nesse sentido, o mercado de carbono desempenha um papel fundamental: pode, em muitos casos, atuar com o objetivo de viabilizar economicamente a implementação de projetos do MDL.

\subsection{O mecanismo de desenvolvimento limpo}

O Mecanismo de Desenvolvimento Limpo (MDL), criado na COP-3, em Quioto, é fruto de uma proposta brasileira à CQNUMC. De fato, a proposta de criação de um Fundo de Desenvolvimento Limpo transformou-se no MDL, definido no artigo 12 do Protocolo de Quioto e regulamentado pelos Acordos de Marraquexe durante a COP-7, que teve lugar no Marrocos.

Dispõe o artigo 12, item 3, do Protocolo de Quioto sobre o MDL: 
(a) As Partes não incluídas no Anexo I beneficiar-se-ão de atividades de projetos que resultem em reduções certificadas de emissões (RCE); e

(b) As partes incluídas no Anexo I podem utilizar as reduções certificadas de emissões, resultantes de tais atividades de projetos, para contribuir com o cumprimento de parte de seus compromissos quantificados de limitação e redução de emissões, assumidos no Artigo 3, como determinado pela Conferência das Partes na qualidade de reunião das Partes deste Protocolo.

O objetivo do MDL é auxiliar as Partes Anexo I (países desenvolvidos com metas de redução de emissões) a cumprir uma porção de seus compromissos de redução e limitação de emissões de GEE por meio do financiamento de projetos e da transferência de tecnologias limpas para a promoção do desenvolvimento sustentável ${ }^{5}$ em países em desenvolvimento. Da forma como foi criado, o MDL é o único dos três mecanismos de flexibilização definidos pelo Protocolo de Quioto que permite a participação de países em desenvolvimento.

No contexto do MDL, atividades de projeto são aquelas que integram um empreendimento cujo objetivo é a redução de emissões de GEE e/ou a remoção de $\mathrm{CO}_{2}$. Essas atividades de projeto estão ligadas exclusivamente a determinados tipos de GEE e aos setores energéticos, de transporte e de floresta, responsáveis pela maior parte das emissões, de acordo com o Anexo A do Protocolo de Quioto.

Podem participar de uma atividade de projeto do MDL as "Partes Anexo I", as "Partes não Anexo I" ou entidades públicas e privadas dessas Partes, desde que tenham autorização das Partes para isso. As atividades de projeto do MDL podem ser implementadas por meio de parcerias com o setor público ou privado. As organizações não governamentais $(\mathrm{ONG})$ podem ter como objetivo a aquisição de Reduções Certificadas de Emissões (RCE) sem objetivo de revenda, retirandoas simplesmente do mercado, com fins estritamente ambientais.

Os participantes de atividades de projeto podem ter como fim a comercialização/revenda das RCE com a expectativa de valorização futura e de realização de lucros, em função da demanda pelas partes que possuem compromissos de redução de emissões. Na prática, o setor privado tem maior possibilidade de participação, pois seu potencial na redução de emissões nesse setor é significativo, bem como é receptor de fluxos crescentes de investimentos que podem ser destinados a atividades de projeto do MDL - um mecanismo de mercado concebido para ter sua ativa participação.

Com a introdução do MDL, as empresas que não conseguirem (ou

\footnotetext{
5 No mesmo sentido do Relatório Brundtland: "o desenvolvimento que satisfaz as necessidades presentes, sem comprometer a capacidade das gerações futuras de suprir suas próprias necessidades" (WORLD COMMISSION ON ENVIRONMENT AND DEVELOPMENT, 1981). Existe uma vasta literatura sobre esse tema, cuja discussão não é objetivo deste trabalho.
} 
não desejarem) diminuir suas emissões poderão comprar RCE nos países em desenvolvimento que tenham gerado projetos redutores de emissão de GEE (florestamento, reflorestamento, biocombustíveis, etc.) e usar esses certificados para cumprir suas obrigações, ainda que o uso desse mecanismo esteja limitado a uma parcela de seus compromissos de redução. As vantagens para o participante estrangeiro consistem na possibilidade de cumprimento parcial de suas metas de redução a um custo marginal relativamente mais baixo.

Os países em desenvolvimento, por sua vez, devem utilizar o MDL para promover seu desenvolvimento sustentável, além de se beneficiarem do ingresso de divisas por conta das vendas de RCE para os países desenvolvidos. Os projetos que se habilitam à condição de projeto de MDL devem cumprir uma série de procedimentos até receber a chancela da Organização das Nações Unidas (ONU), por intermédio do Conselho Executivo do MDL, instância máxima de avaliação de projetos do MDL.

Antes de iniciar a elaboração de um projeto do MDL, seu proponente (quem desenvolve o projeto) deve observar que a participação nesse projeto deve ser voluntária, ou seja, não são aceitos projetos induzidos ou desenvolvidos em decorrência de legislação governamental que retire a natureza espontânea do empreendimento.

Na fase de elaboração do Documento de Concepção do Projeto (DCP), além da metodologia de monitoramento que deve ser utilizada para verificar o cumprimento das metas de redução de emissões e/ou de remoção de dióxido de carbono equivalente $\left(\mathrm{CO}_{2} \mathrm{e}\right)$, é necessário que o proponente estabeleça a adicionalidade e a linha de base do projeto para tornar o projeto elegível.

A adicionalidade significa que as atividades de um projeto do MDL serão consideradas adicionais se as emissões antropogênicas de $\mathrm{CO}_{2} \mathrm{e}$ forem menores do que as que ocorreriam na ausência desse projeto ou se a remoção de $\mathrm{CO}_{2} \mathrm{e}$ da atmosfera for superior àquela que ocorreria quando da inexistência do projeto do MDL. A linha de base constitui o cenário representativo das emissões/remoções antropogênicas de $\mathrm{CO}_{2}$ e que ocorreriam na ausência de projetos MDL.

Pronto o DCP, o participante do projeto deve contratar uma empresa especializada independente (Entidade Operacional Designada (EOD)), devidamente reconhecida pelo Conselho Executivo da $\mathrm{CQNUMC}^{6}$, para revisar (validar) o documento e analisar outras informações relevantes, como comentários das partes interessadas e possíveis impactos socioambientais decorrentes da

\footnotetext{
${ }^{6}$ Órgão supremo do MDL. No Brasil, é representado pelo Conselho Interministerial de Mudança Global do Clima (CIMGC). A comissão é constituída por onze ministérios e coordenada pelo Ministério da Ciência e Tecnologia.
} 
implantação do projeto. A validação é o processo de avaliação independente de um projeto do MDL, por parte de uma EOD, no tocante aos requisitos próprios desse mecanismo, conforme estabelecido na Decisão 17/CP.7 e nas decisões pertinentes à Conferência das Partes, com base no DCP.

A aprovação do projeto do MDL no país hospedeiro é efetuada pela Autoridade Nacional Designada (AND) e corresponde à aceitação da atividade do projeto do MDL pelo governo nacional. No Brasil, a AND é a Comissão Interministerial de Mudança Global do Clima, que tem como atribuição verificar se os projetos estão consistentes em relação a seu objetivo duplo: a) redução das emissões de GEE e/ou remoção de $\mathrm{CO}_{2}$ atmosférico; b) promoção do desenvolvimento sustentável.

Após a aprovação, o projeto segue para o registro, que é a aceitação formal, pelo Conselho Executivo, de um projeto validado como uma atividade de projeto sobre o MDL pela EOD. O registro é pré-requisito para verificação, certificação e emissão das RCE relativas a essa atividade de projeto.

Uma vez registrado no Conselho Executivo, o projeto passa para a fase de monitoramento. Esse procedimento deve seguir um plano estabelecido pela metodologia definida no projeto, produzindo-se relatórios a serem submetidos à EOD para verificação.

A verificação é a revisão independente e periódica e a apuração ex post, efetuada pela EOD, das reduções monitoradas das emissões antrópicas de GEE que ocorreram em consequência de atividade registrada do projeto do MDL durante o período de verificação.

Finalmente, a certificação é a garantia, dada por escrito pela EOD, de que, durante o período de tempo especificado, certo projeto em operação atingiu as reduções das emissões antrópicas de GEE, conforme verificado. Com a certificação, torna-se possível requerer ao Comitê Executivo a emissão das RCE relativas à quantidade reduzida e/ou removida. Essas RCE têm validade determinada e, conforme o caso, podem ser renovadas.

Os mecanismos adicionais de implementação vão estimular o desenvolvimento de um novo mercado internacional, cuja mercadoria é constituída pelas reduções certificadas de emissões de gases de efeito estufa e/ou remoções de $\mathrm{CO}_{2}$. As Partes que possuem compromissos e metas de redução (Anexo I) deverão ser os principais participantes desse mercado, pelo lado da demanda. No caso específico do MDL, os países em desenvolvimento deverão desempenhar um papel significativo nesse mercado, sobretudo na oferta de reduções de emissões de GEE e/ou de remoções de $\mathrm{CO}_{2}$. 
Para os países em desenvolvimento, como o Brasil, o estímulo proveniente desse mercado concentrar-se-á nas atividades de projeto elegíveis e realizadas no âmbito do MDL. Em relação à possibilidade de investimentos originados nos próprios países (projetos unilaterais), espera-se que boa parte do investimento destinado às atividades de projeto do MDL venha do exterior, fomentando o investimento externo direto.

As Partes não Anexo I que tiverem ratificado o Protocolo de Quioto poderão participar, voluntariamente, de atividades de projeto no âmbito do MDL. No caso específico das Partes Anexo I, somente são elegíveis para a participação em atividades de projeto do MDL aquelas que a) tenham suas quantidades atribuídas devidamente calculadas e registradas, b) tenham um sistema contábil nacional para gases de efeito estufa em vigor, c) tenham criado um Registro Nacional e d) tenham enviado o Inventário Nacional de GEE à CQNUMC.

Em resumo, para a aprovação e o registro de um projeto MDL, é necessário o cumprimento dos seguintes critérios de elegibilidade:

a) participação voluntária;

b) benefícios reais, mensuráveis, de longo prazo, adicionalidade e linha de base;

c) desenvolvimento sustentável.

\subsubsection{A experiência brasileira na utilização dos projetos do MDL}

As atividades de projeto estão divididas em pequena e em larga escala. Segundo os Acordos de Marraquexe, são de pequena escala as seguintes atividades de projeto:

a) atividades de projeto de energia renovável com capacidade máxima de produção equivalente a até 15 megawatts (ou equivalência adequada);

b) atividades de projeto de melhoria da eficiência energética, que reduzam o consumo de energia do lado da oferta e/ou da demanda, até o equivalente a 15 gigawatt/hora por ano;

c) outras atividades de projeto que tanto reduzam emissões antrópicas por fontes quanto emitam diretamente menos do que 15 quilotoneladas equivalentes de dióxido de carbono por ano.

As outras atividades serão, então, classificadas como atividades de projeto de larga escala. Considerando-se o tipo de metodologia, a maioria dos projetos brasileiros insere-se nas atividades de projeto desenvolvidas em larga escala.

Serão consideradas aprovadas com ressalva as atividades de projeto cuja contribuição para o desenvolvimento sustentável for considerada adequada, mas 
que apresentem erros de edição ou quaisquer incongruências consideradas de menor relevância pelos membros da Comissão.

Serão consideradas em revisão as atividades que necessitem de esclarecimentos quanto à descrição da contribuição para o desenvolvimento sustentável ou que apresentem erros de edição ou quaisquer incongruências consideradas relevantes pelos membros da Comissão.

Os primeiros projetos aprovados pela Comissão Interministerial foram o da Nova Gerar - geração de 11,8 milhões de RCE, em Nova Iguaçu (Rio de Janeiro), em novembro de 2004 - e o projeto da Vega - geração de 16.102.938 RCE, ao longo de 17 anos, em Salvador-Bahia -, ambos na área de captação/destruição de gases gerados em aterros sanitários (BRASIL, 2009).

Até 30 de setembro de 2008, um total de 4.352 projetos encontrava-se em alguma fase do ciclo de projetos do MDL no mundo (validação, aprovação e registro). O Brasil ocupa a terceira posição em número de atividades de projeto, com 346 projetos (8\%). Em primeiro lugar, está a China, com 1.571 projetos; em segundo, a Índia, com 1.199 projetos.

Em relação à distribuição por estado das atividades de projeto no âmbito do MDL, a região Sudeste predomina em número de projetos devido à posição dos Estados de São Paulo e de Minas Gerais, com 21\% e 14\%, respectivamente, seguidos pelo Rio Grande do Sul e pelo Mato Grosso, ambos com 9\%.

$\mathrm{Na}$ contribuição global dos GEE que foram reduzidos pelas atividades de projetos no âmbito do MDL desenvolvidas no Brasil, percebe-se que o $\mathrm{CO}_{2}$ é atualmente o mais relevante, seguido pelo metano $\left(\mathrm{CH}_{4}\right)$ e pelo óxido nitroso $\left(\mathrm{N}_{2} \mathrm{O}\right)$. A maior parte das atividades de projeto desenvolvidas no Brasil está no setor energético, o que explica a predominância do $\mathrm{CO}_{2}$ na balança de reduções de emissões brasileiras.

No cenário brasileiro, o maior número de projetos desenvolvidos está na área de geração elétrica e na suinocultura (65\%). Os escopos que mais reduzirão t $\mathrm{CO}_{2}$ e são os ligados a aterro sanitário e geração elétrica e os de redução de $\mathrm{N}_{2} \mathrm{O}$, totalizando $73 \%$ de t $\mathrm{CO}_{2}$ e a serem reduzidas no primeiro período de obtenção de créditos. Isso representa 239.231.324 de t $\mathrm{CO}_{2}$ e do total de redução de emissões das atividades de projeto brasileiras.

Considerando-se a capacidade total instalada das atividades de projeto no âmbito do MDL aprovadas pela Comissão Interministerial de Mudança Global do Clima (CIMGC), no setor de geração de energia elétrica, as áreas energéticas estão distribuídas da seguinte forma: co-geração de biomassa, com 1.111,48 MW, hidrelétricas (UHE), com 1.102,2 MW, e pequenas centrais hidrelétricas (PCH), com 647, 86 MW. 
Em países como a China e a Índia a matriz energética depende muito do consumo de combustíveis fósseis, especialmente do carvão mineral. Eis o diferencial desses países para com o Brasil, que possui uma matriz energética baseada principalmente em fontes renováveis, principalmente hidroeletricidade.

Em termos de reduções de emissão projetadas para o primeiro período de obtenção de créditos, o Brasil ocupa a terceira posição, contribuindo com $6 \%$ do total mundial. É responsável pela redução de 330.722.468 $\mathrm{tCO}_{2} \mathrm{e}-$ que representar, no máximo, 10 anos para projetos de período fixo ou 7 anos para projetos de período renovável. Os projetos são renováveis por, no máximo, três períodos de 7 anos, somando um total de 21 anos.

O Brasil ocupa a terceira posição em número de projetos registrados no Conselho Executivo por país anfitrião. Dos 1.120 projetos registrados, 156 são projetos brasileiros. Quanto à redução de emissões durante o primeiro período de obtenção de créditos dos projetos registrados, o Brasil também ocupa a terceira posição, com 159.097.178 t $\mathrm{CO}_{2}$ e do total mundial de 1.822.279.525 t $\mathrm{CO}_{2} \mathrm{e}$.

No Brasil, o Ministério do Desenvolvimento, Indústria e Comércio Exterior (MDIC) empenhou-se, a princípio, na organização do mercado de carbono no país, por meio da implantação do Mercado Brasileiro de Redução de Emissões (MBRE), criado em setembro de 2005, na Bolsa de Mercadorias e Futuros (BM\&F).

O resultado dessa ação foi o estabelecimento de um banco de projetos para atrair investimentos externos e o estímulo à criação de linhas de crédito e fundos privados (Programa de Desenvolvimento Limpo do Banco Nacional de Desenvolvimento Econômico e Social (BNDES)) para o financiamento desses projetos, bem como a preparação, no setor privado, de projetos de grande impacto, utilizando novas metodologias que contemplem as vantagens competitivas do Brasil. Além dessas ações, também foi implantado um sistema inovador de leilão de créditos de carbono.

O primeiro leilão de créditos de carbono do mundo aconteceu em setembro de 2007 e foi realizado pelo MBRE. Nesse leilão, foram negociados os créditos do projeto Bandeirante de captação de metano em aterro sanitário, ao preço de 16,20 euros por tonelada (ágio de 27,55\% em relação ao preço mínimo fixado pelo edital), tendo sido arrecadado um total de $\mathrm{R} \$ 34$ milhões.

Outro tema importante debatido pelo Ministério é a organização do mercado a termo de créditos de carbono. Será preciso fazer regulamentar esse mercado pela Comissão de Valores Mobiliários (CVM), com o intuito de estabelecer as regras necessárias para que as reduções de emissões esperadas, quantificadas em projetos MDL brasileiros aprovados na Junta Executiva do MDL do Protocolo de Quioto, possam ser traduzidas em valores mobiliários, negociáveis no mercado futuro.

O Brasil apresenta-se como um dos países que se beneficiará por ser 
vendedor de créditos de carbono e alvo de investimentos em projetos engajados na redução da emissão de gases poluentes, como é o caso do biodiesel. De acordo com estimativas do Banco Mundial, o país poderá ter uma participação de 10\% no mercado do MDL, equivalente a US\$1,3 bilhão em 2007.

Dessa forma, a produção de biodiesel pelo Brasil trará benefícios que poderão ser convertidos em vantagens econômicas, pelo acordo estabelecido no Protocolo de Quioto e nas diretrizes do MDL. O ganho decorrente da redução da emissão de $\mathrm{CO}_{2}$, por queimar um combustível mais limpo, pode ser estimado em cerca de 2,5 toneladas de $\mathrm{CO}_{2}$ por tonelada de biodiesel.

\section{O MDL E O MERCADO DE CARBONO}

\subsection{O MDL no contexto do capitalismo e o direito de poluir}

Como vimos, no âmbito do Protocolo de Quioto, os países desenvolvidos assumiram o compromisso de reduzir suas emissões de GEE em pelo menos 5\% abaixo dos níveis de 1990 até o primeiro período de compromisso, entre 2008 e $2012^{7}$.

Para não haver comprometimento das economias desses países, o Protocolo estabeleceu que, caso os países compromissados em reduzir suas emissões não conseguissem atingir as suas metas quantificadas, eles poderiam adquirir créditos de carbono de países em desenvolvimento, por meio do financiamento de projetos do Mecanismo de Desenvolvimento Limpo (MDL).

Como o Protocolo de Quioto baseia-se em metas, essa regra também é válida para países que conseguirem reduzir suas emissões abaixo dos níveis estipulados, pois o excedente dessa redução de emissão poderá ser vendido em Bolsas de Valores e de Mercadorias a outros países ou indústrias que necessitem desses créditos. Denominou-se Mercado de Créditos de Carbono esse sistema, que é baseado em projetos de sequestro ou mitigação de GEE.

A partir da implantação desse Mercado, criou-se um certificado de crédito de carbono denominado Redução Certificada de Emissões (RCE), emitido pelas agências autorizadas pela $\mathrm{ONU}$, que tem como meta atestar a redução de emissão de GEE. A quantidade de créditos de carbono recebida varia de acordo com a quantidade de emissão de carbono reduzida. Também ficou definido que uma tonelada de $\mathrm{CO}_{2}$ seria equivalente a um crédito de carbono.

Ocorre que tanto o MDL quanto a forma de comercialização de RCE receberam diversas críticas porque eles concederiam aos países desenvolvidos o direito de poluir. Porém, é necessário questionar se é o conteúdo do MDL que o

7 Cada país tem sua meta e seu limite de poluição (ver Protocolo de Quioto). 
faz ser um instrumento que legitima a poluição ou se é o modo como está sendo usado que abre precedência para tanto. Por ser polêmica, vale a pena aprsentar essa discussão ao leitor.

O mercado de carbono é um mercado de licenças negociáveis de poluição que se fundamenta nas teorias econômicas do "ótimo de poluição" de Pareto e do "direito de propriedade" de Coase (MAIMON, 1993, p. 72).

A primeira teoria parte do princípio de que é legitimamente viável não despoluir totalmente, mas atingir um "nível ótimo de poluição". Além de ser impossível despoluir totalmente, seria extremamente oneroso para o agente econômico mudar o paradigma do seu processo produtivo (poluente). Por isso, alguns economistas admitem que só existe poluição quando há uma perda de bem-estar. O ponto ótimo seria encontrado quando o custo de controle da poluição iguala-se ao custo de degradação. Assim, o valor de mercado das licenças negociáveis de emissão tem de ser exatamente igual ao custo marginal de depuração. Então, a linha de corte do "ponto ótimo" da poluição acaba sendo demarcada pela prática de política ambiental de cada país (ARAGÃO, 1997).

Uma vez que é aceitável não despoluir totalmente, é coerente estabelecer cotas de poluição. Então, a teoria do direito de propriedade de Coase encaixa-se como uma luva no mercado de carbono, já que, segundo essa teoria, cada licença ou cota daria direito à emissão de uma quantidade específica de poluição, isto é, ensejaria o direito de propriedade de emisão.

Nesse sentido, o mercado de carbono é uma consequência do Protocolo de Quioto, no qual foi estabelecido um nível máximo permitido de poluição (ótima) socialmente desejável pelos países signatários. Trata-se dos GEE, a fim de mitigar o aquecimento global. Para tanto, o Protocolo divide esse total de emissões em cotas, que assumem a forma jurídica de direitos/licenças que são alocadas ou leiloadas entre os agentes envolvidos.

O mercado de carbono é um mercado complexo que requer um entendimento amplo do ponto de vista econômico, jurídico e ambiental. Tratá-lo sem as devidas considerações pode gerar conclusões precipitadas.

Primeiramente, o Protocolo de Quioto em nenhum momento levanta a bandeira da solução do aquecimento global. Caso assim fosse, o mercado não estaria preparado para aceitar qualquer tipo de negociação. Assim, o Protocolo faz um apelo diplomático para que se adote uma economia com parâmetros menos insustentáveis. Segundo, o estabelecimento de metas de diminuição de emissão e, consequentemente, de cotas de poluição não legitima as poluições geradas para além das devidas cotas. 


\subsubsection{Argumentos contra o MDL}

Segundo Rodrigues (2004), o Mecanismo de Desenvolvimento Limpo apresenta-se como um "negócio interessante" para as Partes Anexo I:

os países ricos, que foram responsáveis pelo desequilíbrio climático, podem cumprir as suas obrigações sem modificar em nada as suas matrizes energéticas, mantendo ou aumentando sua poluição, desde que use, como forma de compensação, os certificados adquiridos pelo financiamento de projetos do MDL.

Pergunta-se: se os países desenvolvidos continuarem usando as mesmas tecnologias poluentes, adianta financiarem projetos sustentáveis em países em desenvolvimento?

Rodrigues (2004) entende que os maiores responsáveis pela poluição acabam encontrando no MDL uma forma de comprar o direito de poluir: afinal, para eles, é mais rentável pagar projetos do que corrigir sua fonte poluidora. Por isso, para Rodrigues (2003), o MDL é um mecanismo sem legitimidade jurídico-ambiental.

Daí a grande discussão para definir se é válido ou não permitir o crédito de carbono como uma commodity ambiental. Quando se tornam títulos transacionáveis em bolsas, os créditos de carbono ficam potencialmente valorizáveis, inclusive no mercado onde ocorrem as operações não registradas em bolsa de valores, conhecido como mercado de balcão ${ }^{8}$. Isso acontece porque o Protocolo de Quioto baseia-se em metas de emissão, permitindo aos países que conseguirem reduzir suas emissões vender o excedente a quem precise cumprir suas metas.

Considerar os créditos como commodities ambientais sugere que a poluição pode ser incluída na contabilidade, não como passivo/prejuízo, mas como ativo/ investimento. Isso não seria adequado eticamente, quando se sabe (graças a comprovações científicas) que o aumento do efeito estufa está aquecendo o planeta e provocando prejuízos relevantes.

Diante do exposto, constata-se que é preciso saber se os países desenvolvidos estão esforçando-se para mudar suas matrizes enegéticas, isto é, se há uma cobrança por parte do Protocolo no sentido de não permitir que o MDL seja apenas um intrumento financeiro no mercado do carbono.

É evidente que qualquer mudança nas matrizes energéticas é extremamente onerosa para o agente poluidor, que prefere investir em projetos em países em desenvolvimento, onde o custo é menor. Se isso se configurar, pode-se falar na existência do "pagar para poluir", já que os projetos de geração de crédito de

\footnotetext{
${ }^{8}$ Essas operações são também conhecidas como "contratos de gaveta", porque as negociações são realizadas diretamente entre os agentes interessados.
} 
carbono seriam apenas um custo a mais do processo produtivo poluente.

É necessário esclarecer que o "pagar para poluir", que algumas pessoas ligam ao MDL, em nada se assemelha ao princípio do poluidor pagador (PPP), princípio norteador do Direito Ambiental internacional, que jamais legitimaria a poluição.

Pelo princípio do poluidor pagador, o poluidor é obrigado a suportar todos os custos da poluição resultante do seu processo produtivo. Com esse princípio, incorporado à ECO-92, a poluição gerada pelo agente econômico não é mais suportada somente pela sociedade, como até então se aceitava. O poluidor terá de esforçar-se para internalizar as externalidades ambientais negativas por meio da adoção de medidas preventivas de controle e de reparação da poluição no curso do seu processo produtivo.

Segundo Rodrigues (2003), para que o MDL não seja um instrumento que legitima a poluição, o mecanismo deveria estar em consonância com o PPP, pois forçaria o poluidor a investir em tecnologias economicamente mais sustentáveis dentro do seu processo produtivo. Quando o agente econômico percebe que é menos oneroso comprar crédito de carbono do que mudar sua tecnologia, o direito de poluir existe para quem compra o crédito.

Para Barbosa e Oliveira (2006, p. 124-125), o Protocolo de Quioto deve ser regido pelos princípios da sustentabilidade e do poluidor pagador:

deve estimular as empresas a reduzirem suas emissões poluentes. Mas estas, regidas pela lógica de mercado, somente atuarão de forma preventiva, quando a despoluição for mais onerosa do que a poluição. Somente nessas condições, e dialeticamente, utilizando-se da lógica liberal, o PPP, em si, afasta-se da lógica liberal e passa a cumprir o seu papel de princípio de proteção ambiental [...].

Então, entender o PPP como um passaporte para a poluição é deturpar seu sentido de criar esforços para a correção de fontes poluidoras. É um princípio que, de certa forma, visa transformar o modo de produção baseado na excreção de dejetos e no uso desmesurado de recursos em um modo de produção menos gerador de externalidades negativas.

\subsubsection{Argumentos a favor do MDL}

Segundo outra linha de argumentos, o Protocolo de Quioto não abre brechas assim tão largas para legitimar o direito de poluir, como parece num primeiro momento.

No artigo 17 do Protocolo de Quioto, está escrito que “[o comércio de emissões] deve ser suplementar às ações domésticas com vistas a atender os 
compromissos quantificados de limitação e redução de emissões”. Isso mostra que nem todas as emissões reduzidas partirão de créditos de carbono, mas terão de fazer parte de esforços domésticos de cada país comprometido.

Dubeux e Simões (apud BARBOSA; OLIVEIRA, 2006, p. 121) esclarecem o sentido da palavra "suplementar":

os mecanismos de flexibilização são instrumentos que visam suplementar as medidas domésticas de redução [...], com base na acepção da palavra, que suplementar quer dizer algo menor que $50 \%$. De acordo com este raciocínio, no mínimo $50 \%$ das reduções deverão ser efetuadas domesticamente, as restantes poderão ser realizadas por intermédio dos instrumentos de flexibilização do protocolo de Quioto.

Do ponto de vista conceitual, o MDL não configuraria um direito de poluir, porque, diferentemente do que Rodrigues (2003) afirmou, os países desenvolvidos terão de realizar esforços domésticos. Com efeito, investir em projetos do MDL pode até ser mais barato que mudar a tecnologia, mas não se torna interessante a longo prazo porque as empresas poderiam estar investindo nelas mesmas, aumentando sua competitividade tecnológica no mercado.

Esse tipo de conclusão está de acordo com a própria lógica de mercado que busca um custo mínimo, para atingir um lucro máximo, o que acaba por incentivar a busca de controles mais efetivos de poluição que custem mais barato que as licenças ambientais.

De acordo com as regras do Protocolo, o "ponto ótimo de poluição" não deverá ser alcançado somente pelo mercado de carbono, visto que a distribuição das cotas de poluição para os países poluidores é inferior ao padrão ambiental desejado, devendo-se recorrer às demais alternativas.

O Protocolo prevê ainda, em seu artigo 17, que "a Conferência das Partes deve definir os princípios, as modalidades, regras e diretrizes apropriadas, em particular para verificação, elaboração de relatórios e prestação de contas do comércio de emissões".

No plano prático, ainda não se sabe cientificamente como o financiamento de projetos de MDL está afetando as empresas poluidoras. Os resultados do Protocolo de Quioto serão apurados após o primeiro período de compromisso. Contudo, é fato que o MDL tem natureza jurídica e econômica, pois gera créditos valorizáveis em bolsa de valores. Então o MDL, assim como os outros instrumentos do Protocolo, são lucrativos.

Quando inserido no mercado de carbono, o MDL é realmente polêmico, porque geralmente as pessoas não querem ver juntos interesses econômicos e ações altruístas. No entanto, vivemos segundo um paradigma economicista; na verdade, 
trata-se, não de altruísmo, mas de comércio. Nele quem realiza ações ambientais positivas, que levam ao desenvolvimento sustentável, recebe uma troca. Então, de certa forma, essa valorização dos créditos, inclusive como commodity, é uma "faca de dois gumes": se o mercado não estivesse caminhando nesse sentido, com certeza não haveria financiamento de projetos.

De certa forma, Coase estava certo quanto à efetividade do mercado de carbono. À medida que o mercado de licenças se torna "competitivo e as firmas maximizam lucros, as emissões serão minimizadas com a introdução de licenças negociáveis". (COASE apud MAIMON, 1993, p. 72). Cabe ponderar que a comercialização de licenças deve ser gerida pelos órgãos competentes para que não seja ultrapassado o volume de cotas.

Em termos de alcance, o diferencial do MDL reside nos próprios princípios pelos quais se pauta: os créditos gerados auxiliam tanto a atingir metas de redução de emissão de GEE quanto a promover o desenvolvimento sustentável. Quanto à natureza econômica e ao "direito de poluir", a questão está, não em ser lucrativo, pois isso é fato, mas em verificar se existe um esforço por parte dos países poluidores para mudar as matrizes energéticas, o que também é ambientalmente viável para eles. Portanto, "enxergar" o crédito de carbono tão-somente como uma commodity para a captação ou a geração de recursos financeiros é ter uma visão restrita e econômica do mercado.

\section{CONSIDERAÇÕES FINAIS}

O objetivo principal deste trabalho era discutir a aplicabilidade do Mecanismo de Desenvolvimento Limpo como mitigador do aquecimento global, sabendo-se que a principal causa do efeito estufa, além das causas naturais, é a ação antrópica.

Com base nisso, foram analisados os mecanismos que estão sendo utilizados como possíveis mitigadores do aquecimento global visando evitar maiores danos em um futuro não muito distante. Esses mecanismos foram propostos por organismos internacionais juntamente com governantes, cientistas, ambientalistas e economistas preocupados com o futuro do planeta.

No atual quadro de mudanças climáticas globais, o papel desempenhado pelas fontes renováveis de energia no controle da poluição e, consequentemente, na redução de emissão de GEE torna-se ainda mais relevante. O problema básico de introdução dessas fontes de energia reside no fato de que, salvo em casos específicos, as tecnologias de energias renováveis ainda não estão suficientemente estruturadas para garantir sua competitividade em relação às fontes de energia 
convencionais, se não houver mecanismos de apoio.

De acordo com a Convenção-Quadro das Nações Unidas sobre Mudanças Climáticas (CQNUMC), o princípio ambiental da precaução é cautela antecipada, ação antecipada ante o risco iminente. A precaução nasce da diferença temporal entre a necessidade imediata de ação e o momento em que se modificarão os acontecimentos científicos.

Nos dias atuais, exige-se que as ações tenham um caráter transformador, por estarem ligadas ao movimento global de mudanças dos paradigmas e da existência humana. Em verdade, ainda restam muitas dúvidas e controvérsias acerca das causas do aquecimento global. Todavia, a comunidade científica está em busca de respostas para a solução desse grave problema.

Contudo, as evidências demonstram que, independentemente do elo desses riscos com os GEE, alguma coisa precisa ser feita. Assim, as partes comprometeramse a criar alguns mecanismos que amenizassem esse problema para as gerações futuras, já que os danos causados são irreversíveis e suas consequências são bem presentes. Com base nisso, o Mecanismo de Desenvolvimento Limpo foi escolhido entre os instrumentos do Protocolo de Quioto para ser analisado como possível instrumento mitigador do aquecimento global e promotor do desenvolvimento sustentável.

O Protocolo de Quioto tem sido um dos principais responsáveis pela adoção de políticas de incentivos a tecnologias de energia renovável em países industrializados, visto que elas também podem ser uma alternativa para obter as reduções de emissão de GEE acordadas no documento. O Protocolo não é apenas um documento, nem tampouco um receituário com fórmulas mágicas para resolver todos os problemas ambientais e sociais; é, antes, um conjunto de normas estabelecidas de forma conjunta pelos governos dos países que o ratificaram. Podese dizer que é resultado de uma conscientização mundial no sentido de que algo tem de ser feito agora para assegurar a existência das gerações vindouras.

Mesmo sendo um mecanismo fomentador do desenvolvimento sustentável, alguns países não o ratificaram por considerarem-no prejudicial à sua economia (como é o caso dos EUA). Além disso, alguns países não foram inclusos no Protocolo como poluidores potenciais. Por esse motivo, tais países, entre os quais o Brasil, não assumiam a responsabilidade pela redução de emissões. Devido a essas discordâncias, já no próximo documento que substituirá o Protocolo de Quioto após o primeiro período de compromisso (2008-2012), uma das propostas a ser negociada será a inclusão desses países, que se comprometerão a reduzir a emissão de GEE.

Entre os mecanismos propostos para mitigação de GEE, o MDL é o 
mais democrático gerado pelo Protocolo, pois atende aos objetivos e princípios da Convenção. Com ele, pretende-se conseguir o desenvolvimento sustentável por meio da cooperação entre países desenvolvidos e em desenvolvimento. Por ser considerado uma das principais ferramentas do Protocolo, o MDL deve ser aprimorado pelas partes, uma vez que ainda possui algumas lacunas a serem supridas.

Devido à sua importância, neste artigo foi dada maior ênfase aos projetos de MDL, ao mercado de carbono e o "direito de poluir". No mesmo contexto, outra questão levantada diz respeito ao modo como está sendo conduzida a participação do Brasil a partir da implantação, pelo MDIC, do Mercado Brasileiro de Redução de Emissões (MBRE) e aos benefícios que o mercado brasileiro de emissões obtém no sistema de créditos de carbono.

É indubitável que o Protocolo de Quioto deu início a uma nova política de cooperação internacional, e o sistema hoje existente está sofrendo modificações profundas visando o desenvolvimento sustentável do planeta.

Em relação ao "direito de poluir" no âmbito do mercado de carbono, constata-se que as críticas feitas nesse sentido têm um fundo de verdade. Porém, o programa também prevê de que os países considerados como os maiores poluidores reduzam suas emissões e que o sistema de crédito de carbono sirva de estímulo para incentivar os países em desenvolvimento, atraídos pelo ganho financeiro, a cuidar melhor de suas florestas e a evitar queimadas, com o intuito de preservar o meio ambiente.

Entretanto, esses alertas e os estímulos financeiros não foram suficientes. Observa-se que algumas empresas, pela sua ganância e pela sua estupidez, continuam a destruir as florestas, esquecendo que as consequências serão muito graves para todos nós e para as futuras gerações. Governos omissos têm permitido que o desmatamento sem controle destrua a nossa maior riqueza, as florestas. Outra atitude digna de repúdio é o fato de governantes de grandes países ignorarem todos os sinais de perigo dados pela natureza contra a vida humana.

O consolo vem das atitudes que estão sendo tomadas com o objetivo de preservar os ecossistemas, dentre as quais se destacam duas, que são de fundamental importância: a adoção imediata pelos governantes de todos os países de medidas para diminuir as emissões de gases poluentes, seja nas indústrias, seja nos transportes, e uma ação conjunta contra o desmatamento sem controle das florestas. O planeta agradecerá.

Por essa razão, a criação do sistema de créditos de carbono desempenha um papel importante quanto à conscientização dos países e de suas indústrias. 
Contudo, isso não será suficiente para solucionar o problema, se não houver vontade de todos os envolvidos e, principalmente, se o mercado de créditos de carbono perder a sua essência, que é a preservação do meio ambiente.

Governos, empresas e sociedade como um todo devem sentar-se juntos e discutir de que forma deverá ser combatido o crime que tem sido cometido contra o meio ambiente e, consequentemente, contra a humanidade, pois está resultando em graves sequelas para as gerações presentes e vindouras.

Se o novo paradigma é a promoção do desenvolvimento sustentável fundamentado na utilização ecologicamente correta dos meios de produção, será necessário mais do que programas de incentivo financeiro vinculados ao meio

ambiente. É fundamental que tenhamos não somente responsabilidades quanto à preservação dos ecossistemas, mas, antes de tudo, que tenhamos consciência coletiva da necessidade de uma mudança imediata, pois as consequências dos erros do passado estão ocorrendo no presente. Certamente, problemas mais graves advirão no futuro.

Desse modo, o MDL precisa assumir o caráter de prevenção, de correção da poluição dos países desenvolvidos, e não somente de compensação do dano com a realização de projetos de MDL. No caso, o Protocolo de Quioto, pai do MDL, deve ser competente para verificar se os países com obrigações de metas estão corrigindo sua fonte excretora de GEE e incentivar o poluidor a corrigir a fonte poluidora. Só, então, o poluidor será protetor do meio ambiente. Logo, o MDL não deve ser apenas um mecanismo de compensação, pelo qual o empreendedor mantém o mesmo processo produtivo poluente. Por todo o exposto, a transformação deverá acontecer de dentro para fora: é preciso, antes de mais nada, que todos tomem consciência da necessidade de promover a sustentabilidade ambiental.

\section{REFERENNCIAS}

ARAGÃO, Maria Alexandra de Souza. O princípio do poluidor-pagador: pedra angular da política comunitária do ambiente. São Paulo: Coimbra, 1997.

BARBOSA, Rangel; OLIVEIRA, Patrícia. O principio do poluidor-pagador no protocolo de Quioto. Revista de Direito Ambiental, São Paulo, v. 11, n. 14, p. 112-132, 2006.

BRASIL. Ministério da Ciência e Tecnologia e Ministério das Relações Exteriores. Protocolo de Quioto: Convenção sobre Mudança do Clima. 1997. Disponível em: <http://www.mct.gov.br>. Acesso em: jan. 2008.

Ministério da Ciência e Tecnologia. Mecanismo de Desenvolvimento

Limpo: guia de orientação. dez 2002. 90 p. Rio de Janeiro: FGV, dez 2002. 90 p. 
Disponível em: <http://www.mct.gov.br>. Acesso em: set. 2007.

Ministério da Ciência e Tecnologia. Manual do MDL para

Desenvolvedores de Projetos e Formuladores de Políticas. 2006. Produzido pelo Ministério do Meio Ambiente do Japão e pela Fundação Centro Global para o Meio Ambiente. Tradução de Anexandra de Ávila Ribeiro. Disponível em: <http://www.mct.gov.bri >. Acesso em: set. 2007.

Ministério da Ciência e Tecnologia. Quarto Relatório de Avaliação do IPCC: mudança do clima. 2007. Tradução de Anexandra de Ávila Ribeiro. Disponível em: <http://www.mct.gov.br>. Versão em inglês disponível em: <http://www.ipcc.ch>. Acesso em: jan. 2008.

Ministério da Ciência e Tecnologia. Contribuição do Brasil para evitar a mudança do clima. 2007. Disponível em: < http://www.mct.gov.br>. Acesso em: jan. 2008.

CAPRA, Fritjof. O ponto de mutação. São Paulo: Cultrix, 2003.

CENTRO DE GESTÃO E ESTUdOs ESTRATÉGICOS. Manual de capacitação sobre mudança do clima e projetos de mecanismo de desenvolvimento limpo. Brasília, DF, 2008.

MAIMON, Dália. A economia e a problemática ambiental. In: VIEIRA, Paulo Freire; MAIMON, Dália (Org.). As ciências sociais e a questão ambiental: rumo à interdisciplinaridade. Rio de Janeiro: APED; Belém: UFPA, 1993. p. 43-77. PORTUGAL. Departamento de Prospectiva e Planeamento (DPP). Cenários. Tendências e Futuros na Economia Global, v. 6, n. 6, set./dez. 2006. O mundo em 2050. Disponível em: <http://www.dpp.pt>. Acesso em: out. 2007.

RODRIGUES, Marcelo Abelha. Protocolo de Kyoto e mecanismo de desenvolvimento limpo: uma análise jurídico-ambiental. Interesse Público, Porto Alegre, v. 5, n. 24, p. 29-38, mar./abr. 2004.

ROMEIRO, Ademar R. Economia ou economia política da sustentabilidade. In: MAY, Peter H.; LUSTOSA, Maria Cecília; VINHA, Valéria da. Economia do meio ambiente. Rio de Janeiro: Campus, 2003. p. 1-29.

WORLD COMMISSION ON ENVIRONMENT AND DEVELOPMENT. Our Common Future. Oxford: Oxford University Press, 1981. Relatório Brundtland. 